\title{
The Credit Regulatory System of Public Investment Agent Construction Project
}

\author{
Wu Yun-na ${ }^{1}$ Wang Heping ${ }^{1}$ Gao Min ${ }^{1}$ Naren Mandula ${ }^{1}$ Chen Jian ${ }^{1}$ \\ ${ }^{1}$ Department of Economics and Management, North China Electronic Power University, \\ Beijing, China
}

\begin{abstract}
China actively carries out the agent construction reform of public investment projects recently. However, several problems occur in its development. In order to further improve the regulatory system, this paper mainly studies regulatory issues. This paper emphasizes on credit to regulate the agent construction. This paper analyses the development status of ACS and proposes the necessity of credit regulatory system at first. And then the concept of coordinated supervision is introduced. At last, the regulatory points are described and credit regulatory process is designed respectively.This paper provides a method for the government to implement regulatory work.
\end{abstract}

Keywords:Public Investment Projects, Agent Credit, Credit Regulatory, Regulatory Process

\section{Introduction}

Traditional project management methods lead to low efficiency, serious waste of resources and so on ${ }^{[1]}$. So China actively carries out the agent construction reform of public investment projects (PIP). Compared to the traditional management model, agent construction system (ACS) will help improve the management level and efficiency of PIP.
However, several problems occur in its development. ACS lacks legal status. And it's lack of consistency in different regions and management mechanism ${ }^{[2]}$. Supervision and management system is incomplete. The regulatory issues in agent projects mainly reflect in two aspects. On the one hand, the regulatory subject is fuzzy, resulting in multiregulatory. On the other hand, the lack of agent construction projects regulatory approaches $^{[3]}$.

This paper studies credit regulatory issues in PIP. At first the agent credit is described. And then coordinated supervision is introduced. The method improves the regulatory system of ACS.

\section{The Relative Regulatory Theories of Agent Credit}

The agent credit is a long-term and comprehensive problem. This paper decomposes the agent credit into schedule credit, quality credit and cost credit.

The industry credit establishment is an important part of the construction of social credit system. The construction industry is a pillar industry of the national economy. In recent years, a series of credit deficiency occur ${ }^{[4]}$. The main reasons for credit deficiency are the incomplete social credit system, low transparency of credit information and the illegalization of credit management ${ }^{[5]}$. 
In order to maintain and standardize the market order, perfect supervision mechanism of agent construction, totally enhance the economic benefits of nonprofit PIP, it is essential to construct the credit supervision system of PIP.

Credit regulatory in construction refers to the construction regulatory agencies monitor the main market players' status of compliance with the building regulations and regulatory documents. The construction regulatory agencies record information about qualification, operation and management, security management and project performance, and then make evaluation $^{[6]}$. In this paper, collaborative regulatory approach is applied. The philosophy of it is strengthening work flow, information flow and material flow of the construction engineering, through work, information collaboration and resource collaboration, to improve performance and achieve their goals ${ }^{[7]}$. The characteristics of PIP is large scale, tight schedule, high investment. The project objectives of schedule, quality and cost are regulatory importance in government regulatory work.

\section{The Construction of Goal-oriented Regulatory System}

For PIP, the government should develop regulatory targets based on the specific content of the agent construction work.

Schedule is one of the essential factors of construction project. Whether the project can be applied within the scheduled time directly relates to the play of project economic benefits. According to the contents of the schedule objective management, the phases of regulatory workflow are as follows:

(1) The phase of pre-construction. This phase mainly inspects the completeness of schedule plan's contents and the level of schedule plan. The foremost inspect of schedule plan's contents are whether there are three level schedules, and whether there are responsibilities distribution system and schedule coordination system. The level of schedule plan mainly focuses on the logical constraint relationship.

(2) The construction stage. The key points of this stage are whether there are effective control methods, schedule change control and claims control. Schedule changes mainly study whether the change process is clear and reasonable, whether the change scope is narrow. Schedule claims concentrate on the claim procedures and the definition of claim responsibilities.

(3) The stage of completion. This phase mainly evaluates the effect of schedule's implementation. The project completion rate is important.

In summary, the regulatory process of schedule credit is shown in Figure 1. Due to the limited space, the other regulatory flow charts are similar.

According to the contents of the quality objective management, the phases of regulatory workflow are as follows:

(1) The phase of pre-construction. The quality of staff, the quality management system, bidding management and design management are important. The quality of personnel includes management ability of project manager and collaboration ability of project team. Quality management system focuses on the integrity of system content. Quality management organizations, quality principles and policies, quality objectives, quality requirements, and the quality work procedures must be included. Bidding management mainly studies the bidding procedures. Design management concentrates on whether the design contract is perfect, whether preliminary design review and construction drawings review are conducted. 


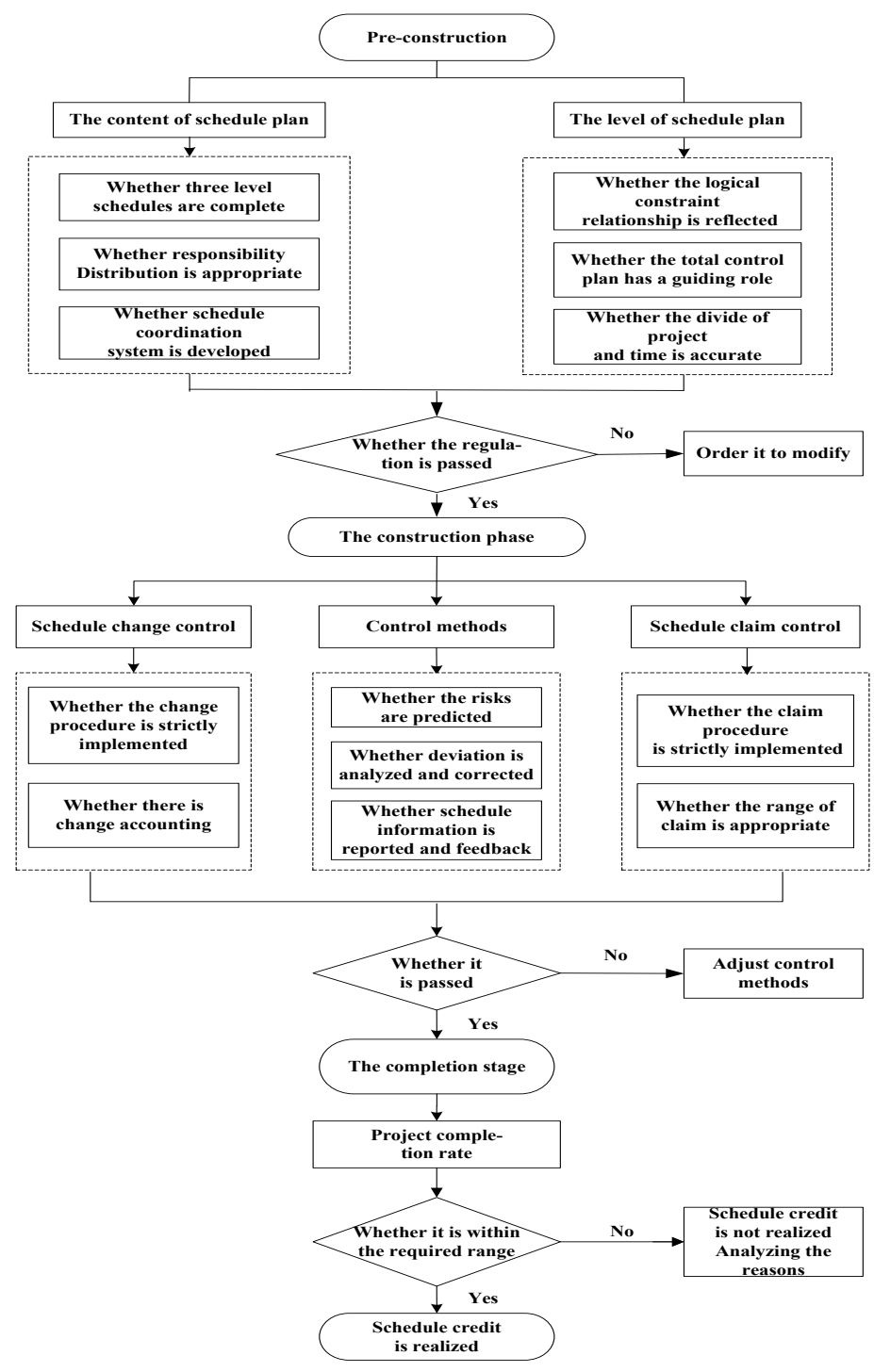

Figure 1. the regulatory process of schedule credit

(2) The construction stage. This stage is divided into the construction preparation phase and the construction process. Construction preparation stage mainly studies the bidding procedures. In the construction process, organizational measures, technical measures and information exchange measures are investigated $^{[8]}$.

(3) The stage of completion. The evaluation of quality plan implementation effect is important in this stage.

The cost goal is to control the cost within investment estimate amount in the 
feasibility study report. The phases of regulatory workflow are as follows:

(1) The phase of pre-construction. This stage mainly concentrates on the total cost control plan, the statement of design management and bidding management. The total cost control plan studies whether the project is scientifically decomposed. Bidding management mainly studies whether a reasonable bidding evaluation committee is established, whether the bidding price is reasonable. Design management focuses on whether there is technical and economic feasibility in design plan.

(2) The construction stage. The implementation status of control methods, the control of cost changes and claims are crucial in this stage. The control methods include organizational measures, technical measures and cost information management. Cost changes mainly examine whether the change and approval procedures are clear and reasonable. Expenses claims mainly concentrate on whether the claims procedures are clear and reasonable, whether the definition of claims responsibility is clear.

(3) The stage of completion. This stage studies the status of the engineering settlement, the final account of completion and the evaluation of cost management effectiveness. The final account of completion examines whether its establishment is in accordance with requirements, whether there is reasonable evaluation. Cost management effectiveness is investigated by the cost change rate.

\section{Conclusion}

This paper designs the agent credit regulatory process against the agent construction development status and characteristic. This method plays a positive role in promoting the relevant government departments to implement the regulatory responsibility and reasonably allocate the regulatory resources.

\section{References}

[1] Duan Yunlong and Shen Xiaojing, "The Study on the Management Mode and Mechanism of Public Investment Project - Take Dianchi Project For Example", Project Management Techniques, pp. 39-42, 2010.

[2] Zhang Jianqiang, "The Regulatory Research on the Agent Construction Projects", China Chongqing: Chongqing University, 2007.

[3] Jin Feng, "The Analysis of Problems in Chinese Public Investment Projects Regulatory", Social Aspect, pp. 168171, 2007.

[4] Lahiru P. Silva, Janaka Y. Ruwanpura, Kasun N. Hewage, "Virtual supervision in construction projects", Building a sustainable futureProceedings of the 2009 Construction Research Congress, pp. 487-496, 2009.

[5] Sun Jingfeng, "Credit Supervision in Construction market - theory, practice and prospect", Construction Economics, pp. 168-171, 2007.

[6] Xiao Lan, "Pipeline Collaborative Management Practice in EPC Project", Refining Technology and Engineering, pp. 61-63, 2012.

[7] Wei Hongsheng, "Supervision System Design and System Implementation", China Beijing: North China Electric Power University, 2008.

[8] Jim. Ernzen, and Tom. Feeney, "Contractor-led quality control and quality assurance plus design-build: Who is watching the quality", Journal of Transportation Research Record, pp. 253-25, 2002. 